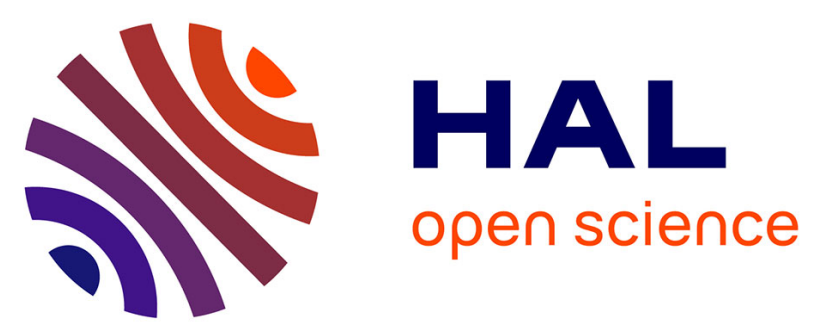

\title{
Transportation of goods in inner-city centers: can autonomous vehicles in platoon be a suitable solution?
}

Franck Gechter, El-Hassane Aglzim, Sidi Mohammed Senouci, Nathalie Rodet-Kroichvili, Cindy Cappelle, Didier Fass

\section{- To cite this version:}

Franck Gechter, El-Hassane Aglzim, Sidi Mohammed Senouci, Nathalie Rodet-Kroichvili, Cindy Cappelle, et al.. Transportation of goods in inner-city centers: can autonomous vehicles in platoon be a suitable solution?. IEEE-VPPC 2017 - Vehicle Power and Propulsion Conference, Dec 2017, Belfort, France. 10.1109/VPPC.2017.8330913 . hal-01772324

\section{HAL Id: hal-01772324 \\ https://hal.science/hal-01772324}

Submitted on 9 Nov 2020

HAL is a multi-disciplinary open access archive for the deposit and dissemination of scientific research documents, whether they are published or not. The documents may come from teaching and research institutions in France or abroad, or from public or private research centers.
L'archive ouverte pluridisciplinaire HAL, est destinée au dépôt et à la diffusion de documents scientifiques de niveau recherche, publiés ou non, émanant des établissements d'enseignement et de recherche français ou étrangers, des laboratoires publics ou privés. 


\section{Transportation of goods in inner-city centers: can autonomous vehicles in platoon be a suitable solution?}

\author{
Franck GECHTER \\ Univ. Bourgogne Franche-Comte \\ UTBM-LE2I \\ Belfort, France \\ Email: franck.gechter@utbm.fr \\ Nathalie RODET-KROICHVILI \\ Univ. Bourgogne Franche-Comte \\ UTBM-FEMTO-ST/RECITS \\ Belfort, France \\ Email: nathalie.kroichvili@utbm.fr
}

\author{
El-Hassane AGLZIM \\ Univ. Bourgogne Franche-Comte \\ ISAT-DRIVE \\ Nevers, France
}

\author{
Sidi-Mohammed SENOUCI \\ Univ. Bourgogne Franche-Comte \\ ISAT-DRIVE \\ Nevers, France
}

\author{
Cindy CAPPELLE \\ Univ. Bourgogne Franche-Comte \\ UTBM-LE2I \\ Belfort, France \\ Email: cindy.cappelle@utbm.fr
}

\author{
Didier FASS \\ University of Lorraine \\ ICN Business School \\ Mosel Loria UMR CNRS 7503 \\ Nancy, France \\ Email: didier.fass@loria.fr
}

\begin{abstract}
The transportation of goods in inner-city centers has become a huge challenge for cities that want to ensure a reliable and efficient service for good delivery with less socioeconomic and ecological impacts. The new opportunities brought by the development of automated functions for vehicles leads to a restructuring of the possible services. The goal of this paper is to present first an overview of the existing solutions for goods transportations systems based on automated and/or alternative solutions and second to sketch the outline and the related issues of a possible solution based on platoon control.
\end{abstract}

\section{INTRODUCTION}

Nowadays, automated driving is playing a leading role in automotive innovations as it opens new ways of auto-mobility. It more concretely represents a high economic value for new functions in passenger cars and commercial vehicles. From a historical perspective, automation in cars was classically related to control tasks. Modern automation furthermore relates to the command of the vehicle and thus concerns active decisions on accelerating and turning. According to the past ten years' evolutions in the domain, we can consider that vehicles autonomous functions and driving assistance devices have now reached a commercial maturity. Despite this, there are still a lot of fields that must be explored by research works. Overviews of the future of vehicle automation can be found in literature and/or in governmental programs. For instance, in the ERTRAC deployment path [1], the actual evolution in vehicle automation leads to an expectation of a spreading of high automated (SRAE 4 [2]) vehicles within the next decade. This estimation is shared by the NFI (Nouvelle France Industrielle) [3] guidelines, which indicates that delivery autonomous transportations systems are expected around 2030 (with a ranked difficulty of 4). Aside to the obvious technological issue related to the subject, the question of replacing the driver by an autonomous system and to avoid an imbalanced "expectation-to-delivery" ratio, research works must include stakeholders from multiple disciplines aimed at exploring socio-economic, psychological, and technical issues. This means that replacing the human driver in the driving task is not as simple as a function exchange. Developing such automation functions necessitates profound competencies of several specific engineering fields, such as environment perception and human machine interfaces. The role of the human driver requires special attention, as he/she no longer represents the single authority in the driving task. Automated Driving brings new dimensions of interdisciplinary engineering in the automotive field. Human Factors thereby appear as particularly critical aspects, as Automated Driving brings Automation into direct contact with society. Along to this ongoing evolution on vehicles point of view, which implies a necessary refinement in engineering processes in Automated Driving, Connected Vehicles and Propulsion/Energy domains [4], [5], new concepts have to be defined on the transportation system point of view. The definition of these new concepts is facing with several issues from the technical to the socioeconomic points of view.

Since several years, a strong effort has been made in order to optimize public transportation systems. This improvement aims at making public transportation more appealing and transforming them into a more competitive alternative to individual cars, which is still the most popular for everyday travels. The fact that the individual car is widespread in dense urban areas lead to unwanted negative side-effects (traffic jams, pollution...) In addition to the improvement of existing modes, new alternative transportation systems appeared. Among them 
one can cite car-sharing, car-rentals, semi-autonomous fleet of vehicles (CRISTAL [6], CATS [7], ... ) ... The delivery of goods in inner centers is also responsible from the same side effects. Along the past years, the regulation of these has been made mainly through specific laws limiting the size and the weight of vehicles and imposing suitable delivery time slots. However, these regulation rules didn't resolve the problems, which are tied to urban transport made by un-adapted vehicles in terms of size and environmental impact. Through the rise of several trends such as the increase of e-business exchanges, the return of small commercial zones and/or the pedestrian friendly programs, this kind of transport is bringing more and more problems. Thus, this final stage of the delivery of goods, known as the "last kilometer issue", corresponds to a huge part of all urban transports. For instance, in 2011, we estimated that these were representing $20 \%$ of the global urban daily traffic in big cities. As a result, the environmental impact has also to be taken into consideration. A 2012 study in the Strasbourg agglomeration noticed that the 233000 weekly travels due to the transport of goods produced 34 000 tons of $\mathrm{CO} 2$. Besides, on a human point of view, these difficulties have also a non-negligible impact on the driver social and safety conditions (time schedule pressure...) This issue is one of the most important challenges for the future of mobility and for the environment efficiency of cities. Due to the number of stakeholders involved, this can be considered as a complex system. Besides, it must face with the will, somehow contradictory, of the consumers, who wants delivery spots as close as possible from their home and a safe and clean living place with little place for the thermal engine vehicles. The goal of this paper is to make an overview of the existing and potential future solutions dealing with the issues related to the transportation of goods in inner-city centres and to propose an innovative conceptual solution based on platoon control algorithm and on the use of the already existing public transportation networks. Along with the presentation of the concept, the paper will also point out the multidisciplinary concerns of such an approach. The paper is structured as follows: Section II is making an overview of the currently existing solutions. Section III is making a state of the art of the platoon control algorithms. Section IV is presenting a new concept of goods delivery system relying on small vehicles able to connect as platoon to the already existing vehicles of the public transportation system. Section V is sketching the main issues the system has to tackle with. Finally, section VI concludes the paper while sketching some perspectives

\section{ALternAtiVE SOLUTIONS FOR THE DELIVERY OF} GOODS

As previously said, the inner city delivery of goods is a major issue for the development of large and medium scale cities [8], [9], [10]. In literature, many projects are dealing with this issue whether on national or international levels. Among these one can cite: The European INTERREG SUGAR [11] project (Sustainable Urban Freight logistics Achieved by Regional and local policies) has mainly focused on the organization of urban distribution of freight taking into account the various policy levers acting in the field of freight transport. The main objectives of the project are the transmission of knowledge and good practices between the research community and the experimental cities (London, Paris, Barcelona, ...) in terms of urban freight. The MetroFreight [12] project (2013-...) is a project conducted by a research consortium involving urban freight, besides the institutional partners, the cities of Paris, New York, Seoul and Los Angeles. Focus of the project is related to the analysis of economic, environmental and governance issues for urban freight partner's territories. The ANR-VD 2010-2014MODUM project [13] (Pooling and Optimization of Urban Transport of Freight) was interested in the functional and organizational study of the Urban Logistics Spaces (ULS) implementation and in particular Urban Distribution Centers (UDC) that appear as one of the most promising approaches for optimizing the delivery of freight by conventional route. These UDC basically allow better filling of vehicles, a reduction in kilometers traveled and thus a reduction of pollution. However, the results obtained in practice on operational UDC in 2012 have not necessarily allowed proving that the cost involved in creating the CDU was completely compensated by the environmental savings. In this context, MODUM project purpose is to analyze, by simulation, the impact of the implementation of CDU and provide tools for the tactical and operational transport planning. The ANR-VBD ANNONA 2013 [14] project (Decision aid for developing sustainable urban logistics plans) is to create tools to evaluate policies to improve urban logistics. These tools are based primarily on creating a body of knowledge of best practices for urban logistics constructed from existing studies on freight transport in the city. The ANR 2014 TCDU project (Collaborative Transport in Urban Distribution) deals with the study of the synergy between the consolidation of logistics flows by the UDC and the consolidation of the flow through collaboration between different transports actors. Alongside these projects, several experiments have already been set up in most major cities. In London, for example, the London Freight Plan aims to improve the transport of freight by proposing a legislative and operational transformation program to take into account future increases in needs. Similarly, in Paris, the city has set up a Freight Action Plan and regularly supports experiments and demonstrations of new practices.

These projects and experiments enable to identify new practices to reduce the impact of freight transport (congestion, pollution, noise...) on city centers. Besides, the use of Urban Distribution Centers that allow to set up a pooling of transport policy, we can classify the innovative alternatives in two main categories: the creation, from Urban Distribution Centers (CDU) of additional grid allowing delivering the last kilometer and based on smaller vehicles with low environmental impact, using the public transport network during peak hours to carry goods. Among the solutions covered by the first category we can mention projects, experiments and services implemented 
in the cities of La Rochelle (ADEME projects Parcel Urban, European Project CityMobil 2), Strasbourg, Rennes, Aixen-Provence, Paris (ADEME Velud Project) ... and based on electric vehicles to make deliveries. In Gothenburg for example, a delivery system for shops in the city center was established in 2012. This system is based on a small size electric driven train enabling the delivery of goods to nearly 500 shops and companies in 2015 (while 8 customers were initially interested in 2012). However, if these solutions significantly reduce noise and air pollution problems, the economic balance of these solutions is not easily achieved.

Among the solutions falling under the second category, we can highlight the freight tram-type solutions in place for example in the cities of Zurich or Paris. These solutions have the main advantage of reusing existing transport network mainly during peak periods. However, they require vehicles with special adjusting. It is also important to note that an effort is also directed at the legislation to promote nocturnal delivery services (Quiet Night-time deliveries program in Barcelona) respecting noise emission constraints imposed by standards such as the PIEK standard [22] for example.

\section{AUtONOMOUS DRIVING IN PLATOONS}

A platoon can be defined as the spatial organization of a vehicles combination in a specific geometric configuration. Depending on application type (urban, agricultural, military, ...), the geometric configuration can take many forms. Configurations are characterized by the lateral and longitudinal gaps between vehicles. When driving a platoon, the vehicles move while keeping, if the environment allows it, the adopted spatial configuration. This capability requires the implementation of sensing functions, control and communication for each vehicle. Most of the time, the platoon control is done either by a local approach (localization relative to a local repository) or a global approach (using an absolute reference).

Among the proposals corresponding to the local approach, we can mention the approaches proposed by Imara [15], the SET-IRTES [16] and LORIA MAIA [17]. As for the global approach, the main element is the perception that can use SLAM algorithms (Simultaneous Localization and Mapping) [18], or existing maps [19]. Each vehicle then follows a global reference (predefined path or directly provided by the first car of the platoon) [20], [21].

Historically, driving in convoy was deployed in the United States under the PATH project (Partners for Advanced Transit and Highways) in 1990-1995. At European level, we can mention the CHAUFFEUR project that aimed to propose heavyweight transport convoys of freights by introducing the concept of leading vehicle driven by a human and towing congeners automatically and in virtual collision. More recently, we can mention, at international level, the SARTRE, FURBOT and InTraDE projects. The SARTRE project [23] located in the continuity of the DRIVER project in terms of application referred. It combines a renowned car manufacturer with institutional and industrial partners. Its main objective is the deployment of embedded technologies for using the convoy driving function.

The InTraDE projects [24] and FURBOT [25] are particularly interested in the delivery of goods. The InTraDE project [26] is interested in improving port productivity (small and medium) of the North West Europe region. The objective is to contribute to national efforts of the European Union governments by diverting traffic from the road to the coastal areas and improving shipping performance in the region. FURBOT project [27] is interested in the development of mobile robotic unit dedicated to freight transport on the last kilometers. Nationally, two projects have run this issue based on Individual Public Vehicles fleet concept in convoy mode and in an urban setting. FCE CRISTAL project (2007-2009) managed by the company Lohr Industrie studied all aspects of the implementation of a self-service vehicle fleet. The study focused on the CRISTAL vehicle with an analysis of mobility management service, territorial impact, and the definition of a station. The ANR-VTT-SafePlatoon project (2011-2014) [28] aimed to study the problem of autonomous vehicle platoon considering applications in urban, agricultural and military. An important aspect of SafePlatoon project lies in the fact that the decision algorithms and control/command proposed were approved by proof tools and validated by simulation and deployed on actual vehicles.

\section{SMAll AUTONOMOUS Vehicle COUPLING INTO A PLATOON WITH PUBLIC TRANSPORTATION VEHICLES: A NEW CONCEPT FOR THE TRANSPORTATION OF GOODS}

The model proposed in this paper describes a delivery system based on the use of small autonomous electrical vehicles for delivering goods in inner city centers collaborating with the already existing public transportations systems (Bus, Tramways...). The main principle of this delivery system relies on a safe and secure platoon control algorithm, which allows a small vehicle to hang virtually to an actor of the public transportation system (bus and/or tramway). Based on this platoon principle, one can imagine an inner city delivery system which uses small electrical vehicles which can use the existing public system and can thus deliver the good as close as possible to the customers (small shops, offices, health professionals...). The path of one delivery vehicle among the network can be computed taking into account the delivery destinations, the network interconnections, a time schedule... so as to reach a good efficiency in the delivery process while disturbing as less as possible the public transportation system. The delivery process could then be the following:

- Loading of the delivery vehicle in a junction center (such as a CDU for instance) between the road station and a public transportation system node.

- The delivery vehicle can then hang to a bus or a tramway with a selection of the line depending on the destination addresses and the temporal constraints (A).

- Once on the target bus/tram stop, the delivery vehicle starts the autonomous un-docking procedure (B). 


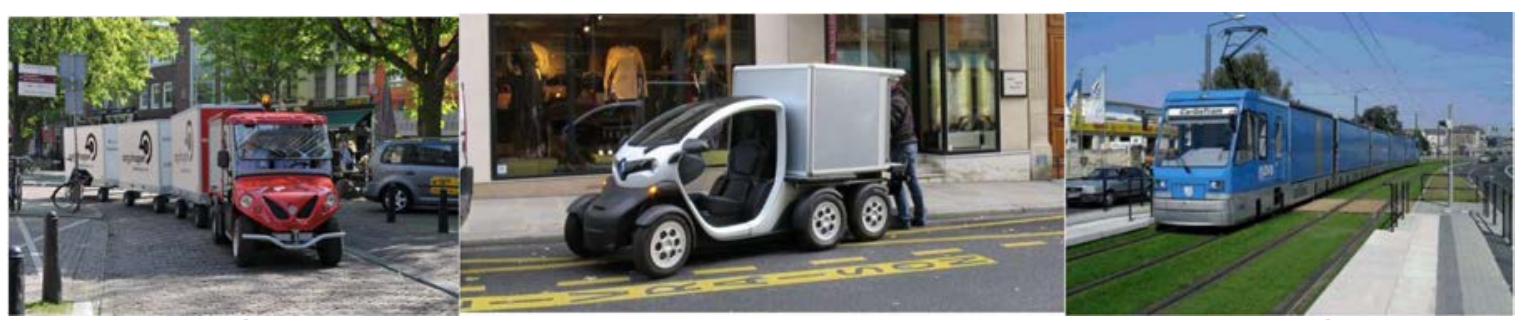

Fig. 1. Current possible alternatives for freight transport in the city center: The electric train in Gothenburg city (left); the electric vehicle project delivery Velud (center) and the Freight tram of Zurich (right).

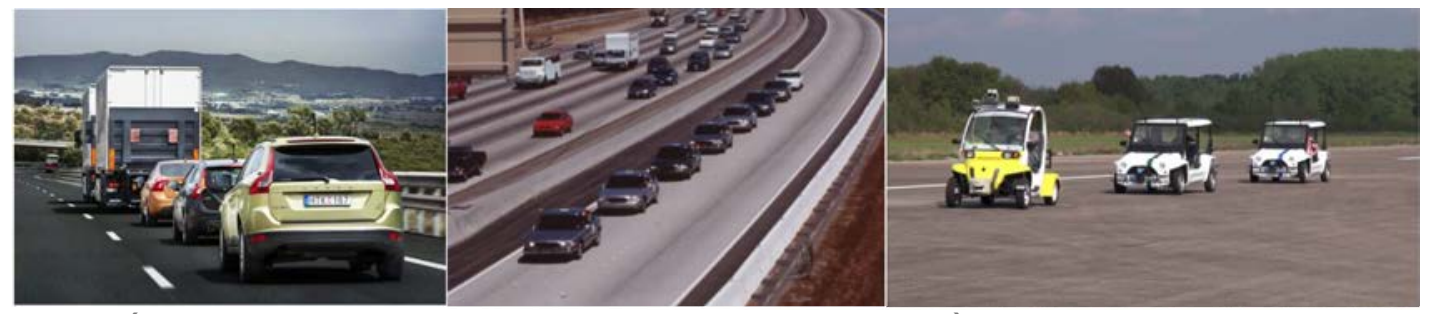

Fig. 2. Several projects dealing with the platoon control issues: Sartre (left), PATH project (center), SafePlatoon project (right)

- The automatic parking process is then starting. The vehicle reaches a reserved place near the bus stop $(\mathbf{C})$.

- The goods are picked up by the receiver. On a technical point of view, the goods can be accessed with a code or a RFID card (D).

- Once the delivery is made, the vehicle can hang to the next bus/tram so has to reach the next delivery point or to return to the junction center $(\mathbf{E})$.

The proposed system has many advantages:

- The system is using an already existing transportation network that is covering a major part of the commercial areas.

- There is no need to introduce a new transportation network that generally leads to a shift of the traffic jam from the main pathways to the secondary roads.

- If the transition phases are smooth and fast enough, there will be no impact on the existing public transportation system.

- The system can adapt to the demand through time and space.

- The system will be available at any time of the day (avoiding the use of regulation time for the delivering of the goods.

- The size of the vehicles is small enough so as to have a better smooth integration in the urban structure.

- The vehicles are clean powered and the docking areas can be used as charging points for the batteries.

- If the first target is the delivery of goods for shops, other use can be found such as providing an inner-city shipping service for restaurants, for administrations...

\section{ONE SOLUTION : MULTI-DISCIPLINARY ISSUES}

Despite all these positive items, the system is facing to several issues related to sociological, business, logistics, technical and human-machine interaction topics and that have to be dealt with so as to make the concept a reality.

From a socio-economic point of view, the main concern is to figure out whether the proposed delivery system provides an appropriate answer to existing needs and could be developed as a profitable and sustainable business compared to alternative solutions. This requires to examine the value provided (or withdrawn) not only to end customers (the inner city commercial areas in our case) but also to other stakeholders taking part or impacted by this delivery system.

On a technical point of view, issues are related to both vehicle level and system level. At vehicle level, the issues are similar to those tied to autonomous vehicles (environment and obstacle perception, control/command algorithms, communications $\mathrm{V} 2 \mathrm{X} . .$.$) but are also strengthened by the$ dynamical constraints linked to the use in association with other vehicles in the public space. They also include energy constraints for maintaining the system operability the whole day, involving the development of efficient and fast charging solutions when the vehicle is docked at the station. At system's level, the main concerns are linked to the optimization of the delivery process taking into account the already existing public transportation system schedule and the requirements of the dead end customers.

Finally, on a human integration point of view, two main aspects have to be explored. The first one is tied to the use of the system and its acceptance by the public. The second one addresses how humans that will interact the most with the delivery vehicles, i.e. the drivers of the buses or the trams, will influence the whole system. The integration 


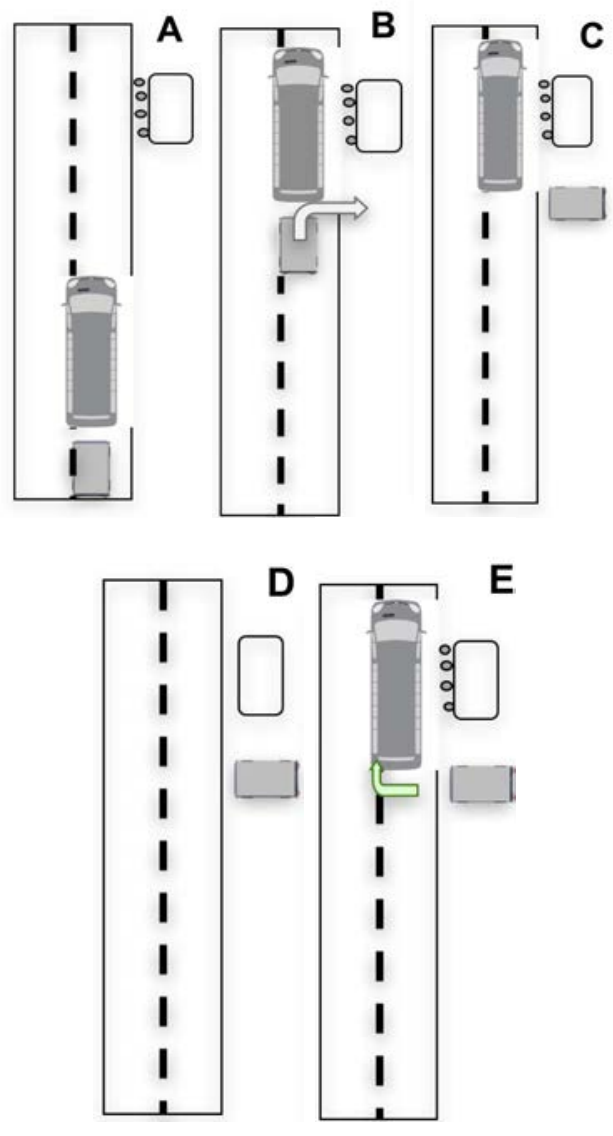

Fig. 3. System's principle

of the human factor requires then innovative models and conception processes so as to develop technical and sociotechnical systems aimed at helping the driver in his/her tasks and avoiding any additional disturbance due to the system especially in the docking phases.

\section{CONCLUSION AND PERSPECTIVES}

Among the possible new solutions related to the more and more widely use of autonomous functions, the solution proposed in this paper seems to be relevant for several reasons. Among these, the proposed system, since it uses the existing public transportation system, doesn't require the definition of a new network complementary and compatible with the existing one. The vehicles have a small size, preventing the drawbacks tied to the current classical vehicles which are over sized and overloaded, and are eco-compliant avoiding then pollution-related side effects. Finally, besides the proposed use for regular goods delivery, the system can provide additional services. Obviously, before having this system operational, several multi-disciplinary issues must be tackled such as socioeconomic viability, defining suitable business model, adapted human-technical system integration, system optimization, etc...

\section{REFERENCES}

[1] ERTRAC Task Force "Connectivity and AutomatedDriving", "Automated Driving Roadmap,” ERTRAC, 2015
[2] Taxonomy and Definitions for Terms Related to On-Road Motor Vehicle Automated Driving Systems - SAE International, 2014

[3] La voiture sans chauffeur, bientôt une réalité (Note d'analyse France Stratégie, 19 avril 2016) http://www.strategie.gouv.fr/publications/ voiture-chauffeur-bientot-une-realite

[4] J. Bermejo-Alonso, R. Sanz, M. Rodríguez, and C. Hernández, "Ontology-Based Engineering of Autonomous Systems," Sixth International Conference on Autonomic and Autonomous Systems (ICAS), pp. $47-51,2010$

[5] Director, Systems and Software Engineering, "Systems Engineering Guide for Systems of Systems", Department of Defense, Aug. 2008

[6] http://lohr.fr/fr/new-mobilities/cristal/

[7] http://transport.epfl.ch/cats-city-alternative-transport-system

[8] J. Morana, J. Gonzalez-Feliu, "La logistique du dernier kilomètre : les défis d'un transport urbain vert", Revue Gestion (HEC), 2010

[9] J. Allen, G. Thorne, M. Browne, "Good Practice Guide on Urban Freight", BESTUFS, Rijswijk, Pays-Bas, 2007

[10] L. Dablanc, "Goods transport in large European cities: Difficult to organize, difficult to modernize", Transportation Research part A vol. 41 , pp. $280-285,2007$

[11] http://www.sugarlogistics.eu

[12] http://www.splott.ifsttar.fr/valorisation-scientifique/ newsletter-metrofreight/

[13] http://www-lipn.univ-paris13.fr/modum/

[14] http://www.agence-nationale-recherche.fr/projet-anr/?tx lwmsuivibilan_pi2\%5BCODE\%5D=ANR-13-VBDU-0001

[15] Y. Bouchalaa, M. Marouf, M. Abualhoul, E. Pollard, O. Shagdar et F. Nashabasuibi, "WAVE low latency video streaming for platooning safety real-time application", IEEE Vehicular networking conference, 2011

[16] B. Dafflon, F. Gechter, P. Gruer et A. Koukam, "Vehicule platoon and obstacle avoidance: a reactive agent approach", IET Intelligent Transport Systems Journal, vol. 3, pp. 257-264, 2013

[17] J. Yazbeck, A. Scheuer, O. Simonin et F. Charpillet, "Improving nearto-near lateral control of platoons without communication", IEEE-RSI International conference on intelligent robots and systems, 2011

[18] G. Bresson, T. Féraud, R. Aufrère, P. Checchin and R. Chapuis, "Real Time Monocular SLAM with Low Memory Requirements", IEEE Transaction on Intelligent Transportation System, vol 99, pp 1-13, 2015

[19] C. Aynaud, C. Bernay-Angeletti, R. Chapuis, R. Aufrère, C. Debain, N. Karam "Real-Time vehiclelocalization by using a top-down process", International Conference on Information Fusion, July 2014

[20] P. Avanzini, B. Thuillot et P. Martinet, "Urban vehicle plaroon using monocular vision: scale factor estimation", International conference on control, automation, robotics and vision, 2010

[21] J.M Vilca, L. Adouane, Y. Mezouar, "A novel safe and flexible control strategy based on target reaching for the navigation of urban vehicles", Robotics and Autonomous Systems (RAS), 2015

[22] http://www.piek-international.com/

[23] http://www.sartre-project.eu/en/Sidor/default.aspx [24] Intelligent Transportation for Dynamic Environment: projet européen régional [25] Freight Urban RoBOTicvehicle: INRIA project

[24] http://www.intrade-nwe.eu/presentation-project-management

[25] http://www.furbot.eu/objectives.shtml

[26] http://web.utbm.fr/safeplatoon/

[27] H. Chusbrough, Open Innovation - The New Imperative for Creating and ProfitingfromTechnology, Cambridge mas, Harvard Business SchoolPress, 2004

[28] N. Rodet-Kroichvili, F. Picard, K. Cabaret, "New insights into innovation: The business model approach and Chesbrough'sseminal contribution to open innovation", Journal of Innovation Economics, 15, 79-99, 2014 